\title{
Solar light assisted photocatalytic degradation of hazardous and highly water soluble pesticide Methomyl using Flower like nano BiOCl
}

\author{
B. Pare ${ }^{1}$, S. Piplode ${ }^{2 *}$, V. Joshi ${ }^{3}$ \\ ${ }^{1}$ Dept. of Chemistry, J. N. S. Govt. College (Vikram University), Shujalpur, India \\ ${ }^{2 *}$ Department of Chemistry, Govt. Madhav Science College (Vikram University), Ujjain, India \\ ${ }^{3}$ Department of Chemistry, Govt. Madhav Science College, Vikram University, Ujjain, India \\ *Corresponding Author: satish.piplode@gmail.com
}

Available online at: www.isroset.org

Receive $06^{\text {th }}$ Aug 2017, Revised $14^{\text {th }}$ Aug 2017, Accepted $18^{\text {th }}$ Sep 2017, Online $30^{\text {th }}$ Oct 2017

\begin{abstract}
Flower like nano bismuth oxy chloride (BiOCl) was successfully synthesized by a simple hydrolytic method using $\mathrm{Bi}\left(\mathrm{NO}_{3}\right)_{3} .5 \mathrm{H}_{2} \mathrm{O}$ as $\mathrm{Bi}$ source material at room temperature. The as-prepared samples were characterized by X-ray diffraction (XRD), High Resolution Field Emission Scanning Electron Microscope (HR FESEM). The results indicated that the asprepared $\mathrm{BiOCl}$ sample is self-assembled hierarchically with nano sheets. The photocatalytic activity of BiOCl was tested on the degradation of the methomyl under solar light irradiation. The results showed that pesticide molecules could be efficiently degraded over $\mathrm{BiOCl}$ under solar light irradiation.
\end{abstract}

Keywords-BiOCl, Flowerlike, Pesticide, photocatalysis, methomyl, solar light

\section{INTRODUCTION}

Methomyl, $\mathrm{C}_{5} \mathrm{H}_{10} \mathrm{O}_{2} \mathrm{~N}_{2} \mathrm{~S}$, S-methyl N-[(methylcarbamoyl) oxy] thioacetimidate) is a broad spectrum insecticide which belongs to the carbamate family of pesticides. Methomyl is a very toxic and hazardous compound because of its high solubility in water $\left(57.9 \mathrm{~g} / \mathrm{L}\right.$ at $\left.25^{\circ} \mathrm{C}\right)$ [1]. It can easily cause contamination of both ground and surface water resources [2]. Some work already has been done on degradation studies of methomyl using $\mathrm{TiO}_{2}$ photocatalysis [2], [3], [4], [5] [6], [7], [8], [9], ZnO photocatalysis [6], [9], Fenton, PhotoFenton system [2], [6], [10], [11], [12], [13]. A. Zapata et al used commercially available formulation Metomur (20\%, w/v, methomyl) for degradation study using Photo-Fenton system [14].

Excessive uses of pesticides are introduced into the environmental system through crops disinfection, industrial pesticide cleaning, misuse and lack of understanding of their ecological effects. Therefore, they become major pollutants due to their extensive use [15]. Hence more effective, lowercost, robust methods to disinfect and decontaminate waters from source to point-of-use are needed, without further stressing the environment or endangering human health by the treatment itself. Conventional methods of water disinfection and decontamination can address many of these problems. However, these treatment methods are often chemically, energetically and operationally intensive, focused on large systems, and thus require considerable infusion of capital, engineering expertise and infrastructure, all of which precludes their use in much of the world. Furthermore, intensive chemical treatments such as those involving ammonia, chlorine compounds, hydrochloric acid, sodium hydroxide, ozone, permanganate, alum and ferric salts, coagulation and filtration aids, antiscalants, corrosion control chemicals, and ion exchange resins and regenerates and residuals resulting from treatment can add to the problems of contamination and salting of freshwater sources [16].

Photocatalytic degradation of pesticides by solar light in the presence of a suitable catalyst may provide a cost-effective remediation of pesticide contaminated water. The technology is attractive as solar energy is an inexpensive, renewable energy source. Furthermore, it can lead to complete mineralization as well, thereby eliminating potential effects associated with toxic intermediates. The present work aims to study the photocatalytic degradation of methomyl using flower like nano $\mathrm{BiOCl}$ as the photocatalyst in presence of solar radiation. This is the first attempt to degrade any carbamate pesticide using $\mathrm{BiOCl}$ and solar light.

\section{Methodology}

\section{Chemicals:}

All major chemicals were of reagent grade or higher purity (99\%). Methomyl pesticide was purchased from Sigma Aldrich (Methomyl PESTANAL). The pesticide was used as such without further purification. The reagent $\mathrm{Bi}$ 
(NO3)3.5H2O was purchased from AR Merck and $\mathrm{HCl}$ was obtained from Merck. Deionised / double distilled water was used throughout this study.

\section{Synthesis of Nanoparticles:}

$\mathrm{BiOCl}$ samples were prepared by hydrolysing $\mathrm{Bi}\left(\mathrm{NO}_{3}\right)_{3} .5 \mathrm{H}_{2} \mathrm{O}$ at room temperature. $\mathrm{Bi}\left(\mathrm{NO}_{3}\right)_{3} .5 \mathrm{H}_{2} \mathrm{O} \quad(9.7 \mathrm{~g})$ was dissolved in $70 \mathrm{~mL}$ of de-ionized water and stirred at room temperature for $1 \mathrm{~h}$ to form the precursor BiONO3. Then, $40 \mathrm{~mL}$ of $\mathrm{HCl}(1 \mathrm{~mol} / \mathrm{L})$ was added drop wise to the solution for $60 \mathrm{~min}$ and the white precipitates formed were subjected to centrifugal separation and washed several times with deionized water and ethanol until the $\mathrm{pH}$ of the system became neutral. The resulting solid was dried at room temperature [17].

\section{Characterization methods:}

X-ray diffraction patterns (XRD) of the prepared samples were recorded on a PANalytical Empyrean PC equipped with $\mathrm{Cu} \mathrm{K} \alpha$ radiation $(40 \mathrm{kV}, 20 \mathrm{~mA})$. The surface morphology of the samples was observed using High Resolution Field Emission Scanning Electron Microscope (HR FESEM). HR FESEM is from Zeiss, model name ULTRA Plus.

\section{Measurment of Photocatalytic activity:}

Pesticide solution was freshly prepared by dissolving in double distilled/deionized water. Prior to light experiments, dark (adsorption) experiments were carried out to know the extent of adsorption of the pesticide on the catalyst. For solar experiments, pesticide solution of $50 \mathrm{~mL}$ was taken in an open glass reactor $(100 \mathrm{~mm}$ x $50 \mathrm{~mm}$ crystallizing dish) with known amount of the catalyst. The solution was illuminated under bright solar light. Deionized/ double distilled water was added periodically to avoid concentration changes due to evaporation. A PC based double beam spectrophotometer 2202 of Systronics has been used for measuring absorbance at different time intervals. The intensity of light was measured by a Lux meter (Lutron LX-101). The $\mathrm{pH}$ and conductivity of the solution was constantly been monitored using a $\mathrm{pH}$ meter and conductivity meter. $\mathrm{pH}$ was adjusted by the addition of either $\mathrm{NaOH}$ or $\mathrm{H}_{2} \mathrm{SO}_{4}$.

The efficiency of photocatalytic process was calculated as:

$\%$ efficincy $=(\mathrm{Co}-\mathrm{C}) / \mathrm{Co} \times 100$

where $\mathrm{Co}$ is the initial absorbance and $\mathrm{C}$ is the absorbance at different time intervals of photocatalytic process.

\section{RESULTS AND DISCUSSION}

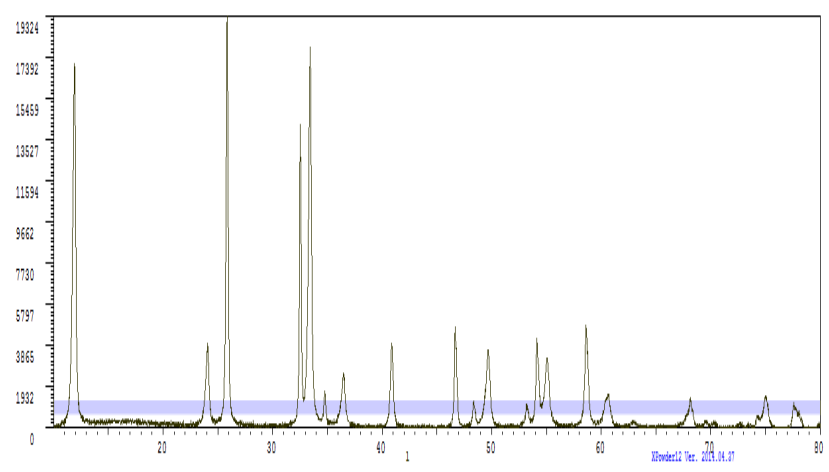

Fig. 1 XRD pattern of flower like nano $\mathrm{BiOCl}$

Fig. 1 shows the XRD pattern of flowerlike nano $\mathrm{BiOCl}$. The hydrolysis prepared $\mathrm{BiOCl}$ was well crystallized. No other diffraction peaks were detected, indicating the high purity of $\mathrm{BiOCl}$. The intense and sharp diffraction peaks suggested that the as synthesized product was well- crystallized. For the $\mathrm{BiOCl}$, the (101), (102), (001) and (110) diffraction peaks are sharper and stronger, while other peaks are relatively weak. This means that $\mathrm{BiOCl}$ should favour to grow along the all the three $\mathrm{x}, \mathrm{y}$ and $\mathrm{z}$ axis [18].

From the $\mathrm{x}$-ray patterns the broadening of the diffraction peaks of the nanoparticles is obvious which is characteristic of nanosized by applying Debye- scherrer formula.

$$
\mathrm{D}=\frac{0.9 \lambda}{\beta \cos \theta}
$$

Where $\mathrm{D}$ is the mean particle size, $\lambda$ is the wavelength of incident $\mathrm{X}$-ray $\left(1.5406^{\circ} \mathrm{A}\right), \theta$ is the degree of the diffraction peak, and $\beta$ is the full width at half maximum (FWHM) of the XRD peak appearing at the diffraction angle $\theta$. The broadening of the absorption spectrum could be due to the quantum confinement of the nanoparticles. The mean calculated crystallite size of the $\mathrm{BiOCl}$ nanoparticles shows that the synthesized nanoparticle is $45 \mathrm{~nm}$.

Fig. 2 shows the HR FESEM image of the flower like nano $\mathrm{BiOCl}$. It can be clearly seen that the $\mathrm{BiOCl}$ particles having Flower like structure. The size of the flower is about 4-6 micrometer.

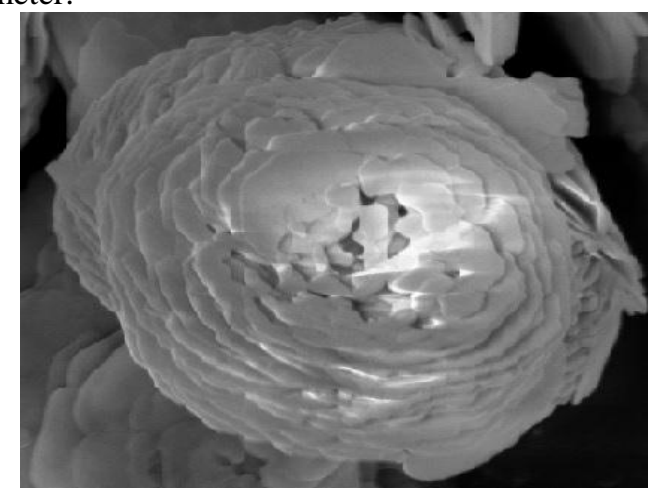

Fig 2 HR FESEM image flower like nano $\mathrm{BiOCl}$

\section{Structural studies:}




\section{Photocatalytic Activity:}

The photocatalytic activities of flower like nano $\mathrm{BiOCl}$ was evaluated through the degradation of $10^{-4} \mathrm{~mol} \mathrm{\textrm {dm } ^ { - 3 }}$ methomyl (MM) in water. To know the photolysis of MM in solar and visible light an experiment carried out and also know the adsorption efficiency of flower like nano $\mathrm{BiOCl}$ catalyst a dark reaction only with $\mathrm{BiOCl}$ carried out along with photocatalysisin the presence of solar and visible light. Fig. 3 shows the results of the experiment. Results had drawn between $\mathrm{C} / \mathrm{C}_{0}$ verses time where $\mathrm{C}$ is the absorbance at a particular time and $\mathrm{C}_{0}$ is the initial absorbance. The results showed that degradation of MM solution very low under visible light and solar light in the absence of $\mathrm{BiOCl}$ and also adsorption of pesticide on $\mathrm{BiOCl}$ surface was low. $\mathrm{BiOCl}$ was unable to initiate the pesticide degradation in dark. Light source induce the photocatalysis process. Degradation of $\mathrm{MM}$ in presence of visible light and $\mathrm{BiOCl}$ not shows the favourable results. Photocatalysis using solar light shows the promising results because both UV and visible lights are present in solar light. Thus it can be assumed that UV light is respossible to initiate the photocatlysis rection. Because $\mathrm{BiOCl}$ is wide band gape semiconductor materials and absorbs only UV light and cannot degrade MM pesticide in visible light theoretically. The results concluded that the photocatalytic degradation of MM using solar light is the favourable method to mineralise the pesticide solution and combination of UV and visible light is responsible to induce the process.

Photocatalysis process depends on experimental condition. To know the effect of operational parameter various experiment such as $\mathrm{pH}$, catalyst amount, pesticide concentration, oxidant $\left.\left(\mathrm{H}_{2} \mathrm{O}_{2}\right), \mathrm{K}_{2} \mathrm{~S}_{2} \mathrm{O}_{8}\right)$ concentration, $\mathrm{FeCl}_{3}$ concentration along with other catalysts and stability of catalyst carried out.

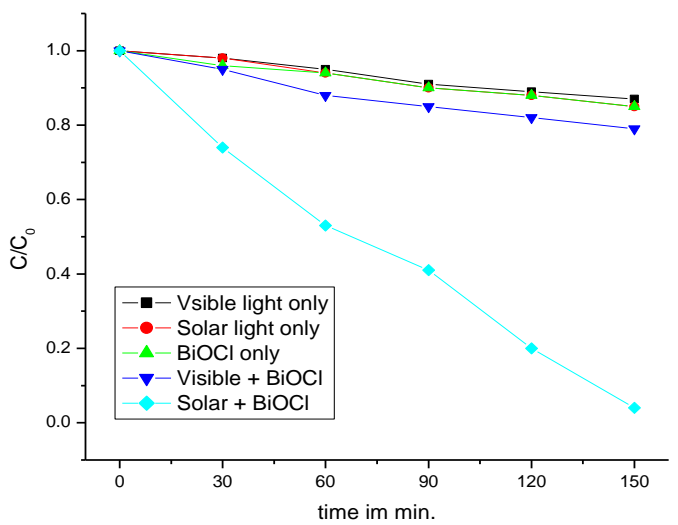

Fig. 3 Degradation study of MM using different system

Experimental condition: $[\mathrm{MM}]=10^{-4} \mathrm{~mol} \mathrm{dm}^{-3}, \mathrm{BiOCl} \mathrm{NPs}=$ $40 \mathrm{mg} / 50 \mathrm{ml}, \mathrm{pH}=6.3$

\section{Effect of $\mathrm{pH}$ :}

$\mathrm{pH}$ is one of the most important parameters for the photocatalytic processes. The effect of $\mathrm{pH}$ on activity of $\mathrm{BiOCl}$ was studied. As it can be seen from Fig. 4 when the $\mathrm{pH}$ of the solution, containing pesticide and $\mathrm{BiOCl}$ is varied from 2.2 to 12.3 , the photocatalytic degradation efficiency reached a maximum at $\mathrm{pH} 6.3$ followed by a decrease of kinetic rate constant in the $\mathrm{pH}$ range 6.3 to 12.3 . This behaviour can be explained by the surface charge of $\mathrm{BiOCl}$ as a function of $\mathrm{pH}$ and attack of hydroxyl radical [19].

Effect of $\mathrm{pH}$ variations: $[\mathrm{MM}]=10^{-4} \mathrm{~mol} \mathrm{dm}^{-3}, \mathrm{BiOCl} \mathrm{NPs}=$ $40 \mathrm{mg} / 50 \mathrm{ml}$

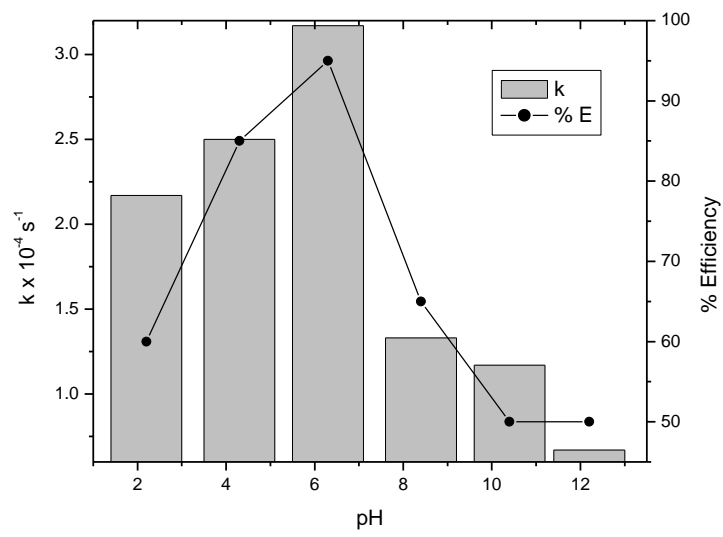

Fig. 4 Effect of pH on photocatalytic degradation of MM

\section{Effect of Catalyst Loading:}

In order to avoid excess catalyst and ensure total absorption of efficient photons optimum catalyst concentration has to be determined. Thus the effect of photocatalyst weight on the photodegradation of the pesticide was studied in the range of $20 \mathrm{mg} / 50 \mathrm{ml}$ to $70 \mathrm{mg} / 50 \mathrm{ml}$ and results are plotted in Figure. The graph shows that as the concentration of catalyst increased from $20 \mathrm{mg} / 50 \mathrm{ml}$ to $40 \mathrm{mg} / 50 \mathrm{ml}$, the degradation rate constant increased from $1.67 \times 10^{-4} \mathrm{~s}^{-1}$ to $3.17 \times 10^{-4} \mathrm{~s}^{-1}$ but on increasing the catalyst concentration up to $70 \mathrm{mg} / 50 \mathrm{ml}$, the rate constant decreased to $1.5 \times 10^{-4} \mathrm{~s}^{-1}$ respectively. The optimum weight of catalyst loading was found to be $40 \mathrm{mg} / 50 \mathrm{ml}$. The increased degradation rate that follows the increase in the catalyst weight can be attributed to the fact that the total active surface area increases with increasing catalyst weight, thus accelerating the process. The decrease in efficiency may be due to an increasing opacity of the suspension and to an enhancement of the light reflectance, because of the excess of $\mathrm{BiOCl}$ particles. Additionally, in the case of high catalyst loads, we observed agglomeration and sedimentation of $\mathrm{BiOCl}$ which makes a significant fraction of catalyst to be inaccessible to either absorbing the pesticide or absorbing the radiation, with 
consequent decrease in active sites available to the catalytic reaction [20].

Effect of catalyst loading: $[\mathrm{MM}]=10^{-4} \mathrm{~mol} \mathrm{dm}^{-3}, \mathrm{pH}=6.3$

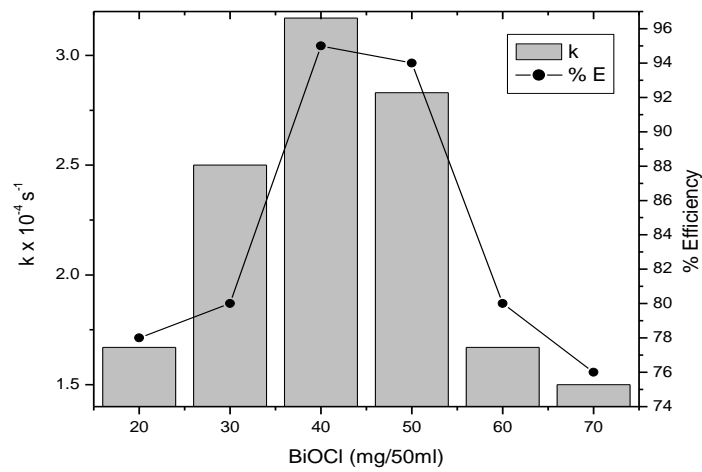

Fig. 5 Effect of catalyst loading on photocatalytic degradation of MM

\section{Effect of pesticide concentration:}

Effect of pesticide concentration was also studied by taking different concentrations of pesticide from $0.6 \times 10^{-4} \mathrm{~mol} \mathrm{dm}^{-3}$ to $2.6 \times 10^{-4} \mathrm{~mol} \mathrm{dm}^{-3}$. The results are shown in Fig. 6. It was observed that the rate of photocatalytic degradation increased with increasing concentration of the pesticides upto $10^{-4} \mathrm{~mol}$ $\mathrm{dm}^{-3}$. This might be attributed to the fact that as the concentration of pesticides increased, more pesticide molecules were available for excitation followed by inter system crossing and hence, there was an increase in the rate. On further increase in pesticide concentration, the equilibrium adsorption of pesticide on catalyst surface active sites increases, which hinders the competitive adsorption of $\mathrm{OH}^{-}$on the same sites, which means a lower formation rate of $-\mathrm{OH}$ radicals. The increase in pesticide concentration also decreases the path length of photons entering the pesticide solution. At high pesticide concentration, a significant amount of UV and visible light may be absorbed by the pesticide molecules rather than the catalyst and this may also reduce the catalytic efficiency. Consequently, the degradation rate decreased to $0.16 \times 10^{-4} \mathrm{~s}^{-1}$ as the pesticide concentration increased upto $2.6 \times 10^{-4} \mathrm{~mol} \mathrm{dm}^{-3}$ [21].

Effect of pesticide concentration: ,BiOCl NPs $=40 \mathrm{mg} / 50 \mathrm{ml}$, $\mathrm{pH}=6.3$

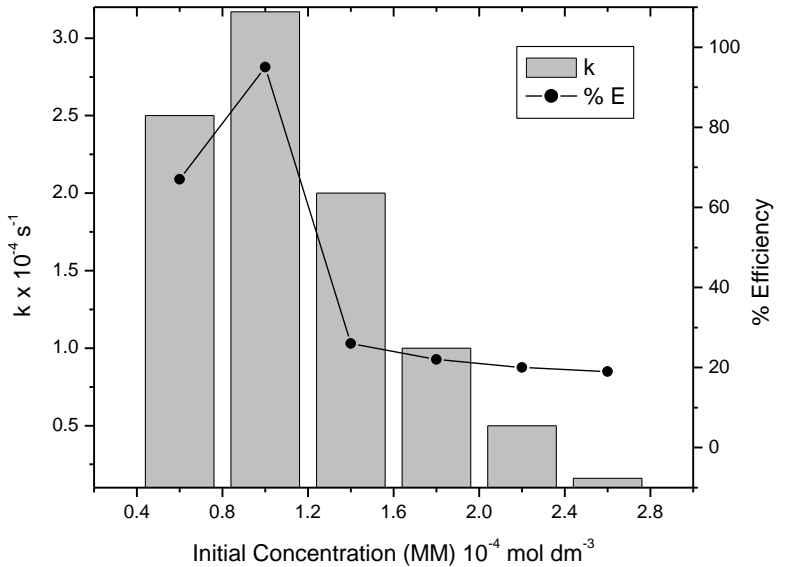

Fig. 6 Effect of initial concentration of MM on photocatalytic degradation of MM

\section{Effect of $\mathrm{H}_{2} \mathrm{O}_{2}$ :}

Fig. 7 shows the relationship between rate constant for the degradation of methomyl and initial concentration of $\mathrm{H}_{2} \mathrm{O}_{2}$. The results indicate that the degradation of methomyl was increased by increasing the concentration of $\mathrm{H}_{2} \mathrm{O}_{2}$. This can be explained by the effect of the additionally produced hydroxyl radicals. With increasing $\mathrm{H}_{2} \mathrm{O}_{2}$ concentration from $2 \times 10^{-6} \mathrm{~mol} \mathrm{dm}^{-3}$ to $4 \times 10^{-6} \mathrm{~mol} \mathrm{\textrm {dm } ^ { - 3 }}$, the rate constant increases but above this range the improvement was not obvious. This may be due to recombination of hydroxyl radicals and also hydroxyl radicals reaction with $\mathrm{H}_{2} \mathrm{O}_{2}$, contributing to the $\cdot \mathrm{OH}$ scavenging capacity (Eqs. (2)- (4)) [22].

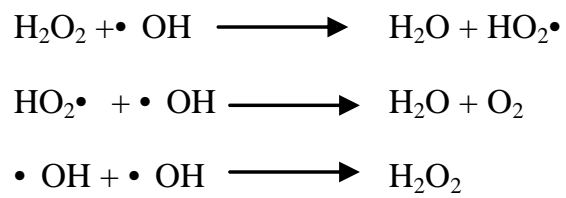

Effect of $\mathrm{H}_{2} \mathrm{O}_{2}$ : $[\mathrm{MM}]=10^{-4} \mathrm{~mol} \mathrm{dm}{ }^{-3}, \mathrm{BiOCl} \mathrm{NPs}=$ $40 \mathrm{mg} / 50 \mathrm{ml}, \mathrm{pH}=6.3$

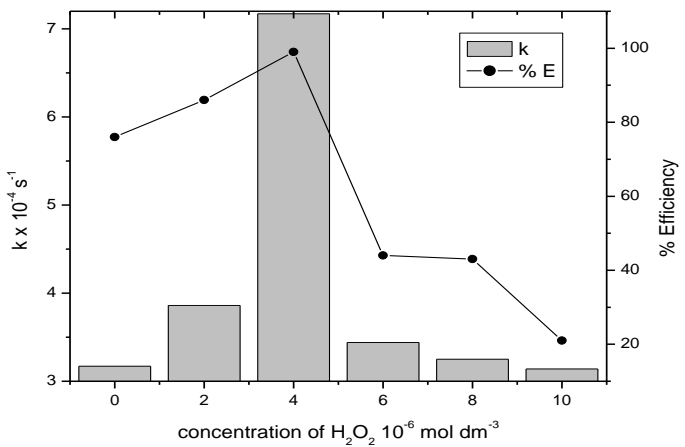

Fig. 7 Effect of $\mathrm{H}_{2} \mathrm{O}_{2}$ on photocatalytic degradation of $\mathrm{MM}$ 


\section{Effect of $\mathrm{K}_{2} \mathrm{~S}_{2} \mathrm{O}_{8}$ :}

$\mathrm{K}_{2} \mathrm{~S}_{2} \mathrm{O}_{8}$ can trap the photogenerated conduction band electron resulting in the formation of sulphate ion $\left(\mathrm{SO}_{4}{ }^{-}\right)$, a strong oxidizing agent which can participate in degradation process. The decrease in rate constant above optimum concentration is due to the adsorption of sulphate ions formed during the reaction on surface of catalyst deactivating a section of photocatalyst (Fig. 4.8) [23]. Amount of sulphate ion $\left(\mathrm{SO}_{4}^{-\cdot}\right)$ is one of the main parameters to influence photocatalytic processes. In this study, to obtain the optimal initial sulphate ion $\left(\mathrm{SO}_{4}^{-}\right)$concentration, the investigation was carried out in the range of $\left(2 \times 10^{-6}\right.$ to $10^{-5} \mathrm{~mol} \mathrm{dm}^{-3}$. The results are shown in Fig. 4.8. It can be seen that degradation rate of methomyl distinctly increased with the increasing amount of sulphate ion $\left(\mathrm{SO}_{4}^{-}{ }^{-}\right)$. So, Degradation process addition of sulphate ion $\left(\mathrm{SO}_{4}^{-{ }^{-}}\right)$at $4 \times 10^{-6} \mathrm{~mol} \mathrm{dm}^{-3}$ increases rate constant of reaction from $3.17 \times 10^{-4} \mathrm{~s}^{-1}$ to $3.75 \times 10^{-4}$ $\mathrm{s}^{-1}$. The rate constant of methomyl began to decrease when the concentration of sulphate ion $\left(\mathrm{SO}_{4}^{-}{ }^{-}\right)$was higher than $4 \mathrm{x}$ $10^{-6} \mathrm{~mol} \mathrm{dm}^{-3}$.

Effect of $\mathbf{K}_{2} \mathbf{S}_{2} \mathbf{O}_{\mathbf{8}}:[\mathrm{MM}]=10^{-4} \mathrm{~mol} \mathrm{dm}^{-3}$, BiOCl NPs= $40 \mathrm{mg} / 50 \mathrm{ml}, \mathrm{pH}=6.3$

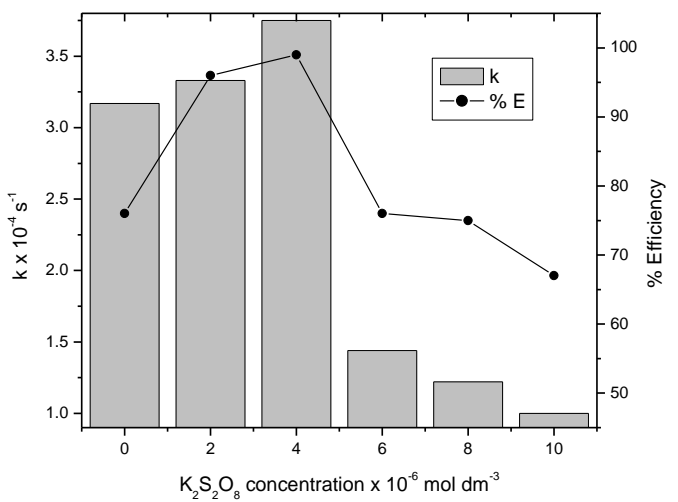

Fig. 8 Effect of $\mathrm{K}_{2} \mathrm{~S}_{2} \mathrm{O}_{8}$ on photocatalytic degradation of MM

\section{Effect of $\mathrm{FeCl}_{3}$ :}

Amount of ferrous ion is one of the main parameters to influence the photocatalytic processes. In this study, to obtain the optimal initial $\mathrm{Fe}^{3+}$ concentration, the investigation was carried out in the range of $\left(2 \times 10^{-6}\right.$ to $\left.10^{-5} \mathrm{~mol} \mathrm{dm}^{-3}\right)$. The results are shown in Fig. 4.9. It can be seen that degradation rate of methomyl distinctly increased with the increasing amount of $\mathrm{Fe}^{3+}$. So, Degradation process addition of $\mathrm{Fe}^{3+}$ at $2 \times 10^{-6} \mathrm{~mol} \mathrm{dm}^{-3}$ increases rate constant of reaction from $3.17 \times 10^{-4} \mathrm{~s}^{-1}$ to $3.83 \times 10^{-4} \mathrm{~s}^{-1}$. The rate constant of methomyl began to decrease when the concentration of $\mathrm{Fe}^{3+}$ was higher than $2 \times 10^{-6} \mathrm{~mol} \mathrm{dm}^{-3}$.

Ferric ion $\left(\mathrm{Fe}^{3+}\right)$ known to behave as an electron scavenger (Eq. (5)) thus preventing the recombination of electron hole pairs. Under the experimental conditions the following reactions become significant.

$\mathrm{Fe}^{3+}+\mathrm{e}_{\mathrm{CB}}^{-} \longrightarrow \stackrel{\mathrm{Fe}^{2+}}{\longrightarrow}$
$\mathrm{Fe} 3++\mathrm{HO}_{2} \bullet+\mathrm{H}^{+} \longrightarrow \mathrm{Fe}^{2+}+\mathrm{H}_{2} \mathrm{O}_{2}$
$\mathrm{Fe}^{2+}+\mathrm{H}_{2} \mathrm{O}_{2}+\mathrm{H}^{+} \longrightarrow \mathrm{Fe}^{3+}+\cdot \mathrm{OH}+\mathrm{H}_{2} \mathrm{O}$

When $\mathrm{FeCl}_{3}$ concentration was in excess of $4.0 \times 10^{-6} \mathrm{~mol}$ $\mathrm{dm}^{-3}$ the degradation rate constant values decreased gradually due to the deposition of $\mathrm{Fe}^{3+}$ ions on the $\mathrm{BiOCl}$ particals. Active sites of the $\mathrm{BiOCl}$ got covered with $\mathrm{Fe}^{3+}$ ions [24].

Effect of $\mathrm{FeCl}_{3}:[\mathrm{MM}]=10^{-4} \mathrm{~mol} \mathrm{dm}^{-3}, \mathrm{BiOCl} \mathrm{NPs}=$ $40 \mathrm{mg} / 50 \mathrm{ml}, \mathrm{pH}=6.3$

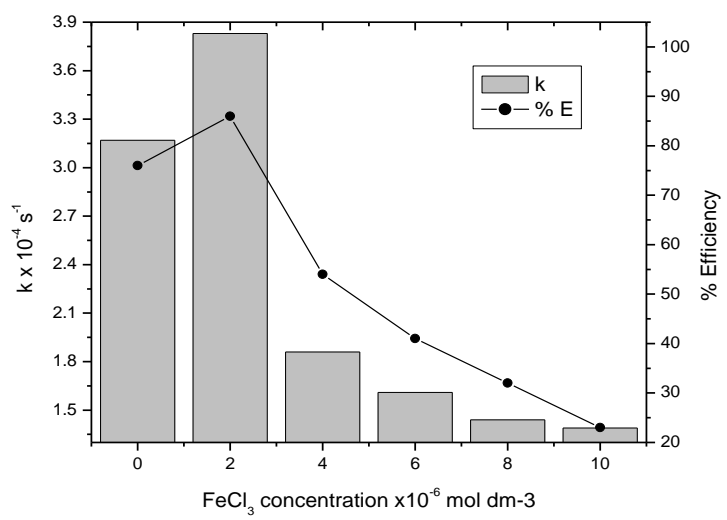

Fig. 9 Effect of $\mathrm{FeCl}_{3}$ on photocatalytic degradation of $\mathrm{MM}$

\section{Effect of other catalyst:}

The effects of various photocatalysts such as flowerlike nano $\mathrm{BiOCl}$, nano $\mathrm{BiOCl}$, bulk $\mathrm{BiOCl}$, bulk $\mathrm{ZnO}$, nano $\mathrm{ZnO}$ on degradation have been investigated at same condition. The results shown in Fig. indicate that $\mathrm{BiOCl}$ exhibits excellent performance in terms of both adsorption and degradation of Methomyl. The highest photocatalytic activity was observed in the presence of flower like $\mathrm{BiOCl}$. The results show that flower like nano $\mathrm{BiOCl}$ is more efficient than other catalyst. The order of activities of the photocatalysts flowerlike nano $\mathrm{BiOCl}>$ nano $\mathrm{BiOCl}>$ nano $\mathrm{ZnO}>$ bulk $\mathrm{BiOCl}>$ bulk $\mathrm{ZnO}$. Hierarchical structures could enhance light utilization significantly because of the multiple reflections of light within the interior structure of the flower like BiOCl. Such enhancements could generate more of electrons and holes and thus that can promote photocatalytic activity in the flower like nano BiOCl sample [25], [26].

Effect of other catalysts: $[\mathrm{MM}]=10-4$ moldm-3, Catalyst= $40 \mathrm{mg} / 50 \mathrm{ml}, \mathrm{pH}=6.3$ 


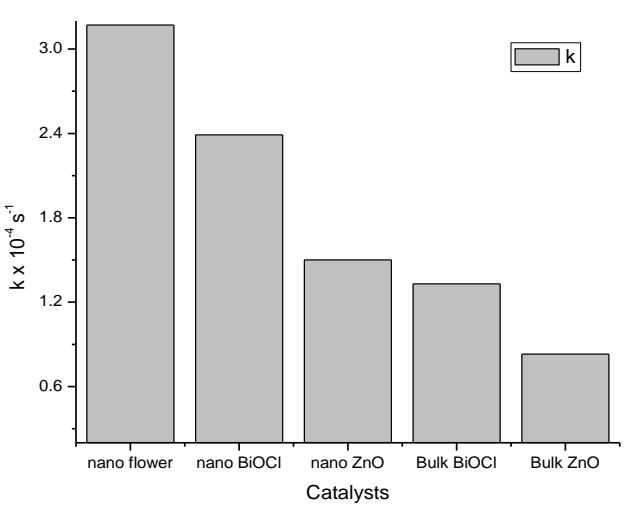

Fig. 10 Effect of other catalyst on photocatalyst degradation of MM

\section{Stability test for BiOCl activity:}

To assess the stability of the $\mathrm{BiOCl}$ in the photocatalytic reaction, $\mathrm{BiOCl}$ was re-examined for two more cycles. As shown in Fig. 11, the photocatalytic performance of the asprepared $\mathrm{BiOCl}$ for $\mathrm{MM}$ degradation was effectively maintained for 120 minutes of testing. After three cycles of repetition tests for photodegradation of MM, catalyst did not exhibit any significant loss of activity. This experimental result indicated that $\mathrm{BiOCl}$ is quite stable and has good photocatalytic performance on degradation of MM [27].

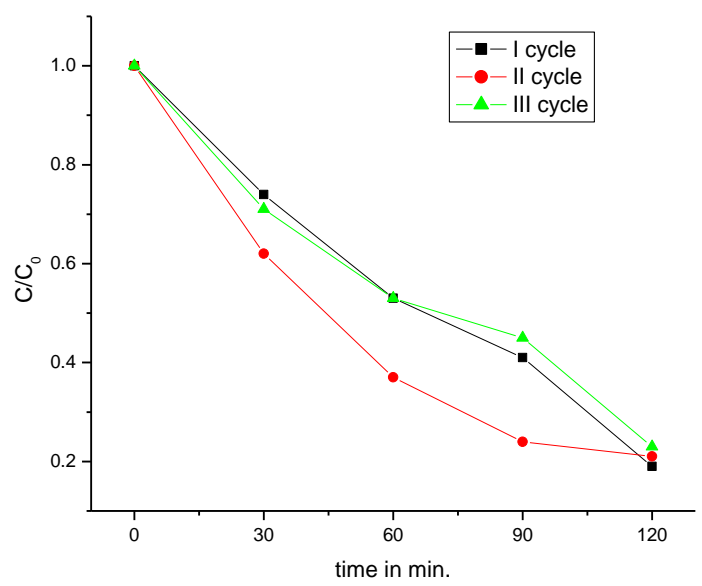

Fig. $11 \mathrm{MM}$ drgradation by $\mathrm{BiOCl}$

Experimental Condition: $[\mathrm{MM}]=10^{-4} \mathrm{~mol} \mathrm{dm}^{-3}, \mathrm{BiOCl}$ $\mathrm{NPs}=40 \mathrm{mg} / 50 \mathrm{ml}, \mathrm{pH}=6.3$

\section{CONCluSION AND Future SCOPE}

Flower like nano BiOCl synthesized by hydrolysed method. $\mathrm{BiOCl}$ shows promising catalytic activity in solar for methomyl pesticide degradation. UV light present in solar light induce the photocatlytic activity of $\mathrm{BiOCl}$.As prepared flower like nano $\mathrm{BiOCl}$ exhibit excellent photocatalytic activity to degrade $\mathrm{MM}$ in $150 \mathrm{~min}$. under experimental condition. Size and morphology plays an important role in photocatalytic activity. Hierarchical structures could enhance light utilization significantly because of the multiple reflections of light with in the interior structure of the flower like nano $\mathrm{BiOCl}$. Such enhancements could generate more of electrons and holes and thus that can promote photocatalytic activity in the flower like nano $\mathrm{BiOCl}$. This work provides an example of size and shape dependent photocatalytic properties and also opens new possibilities to provide some insight into nano sized and hierarchical structure semiconductors photocatalysts for degrading organic pollutants and other applications.

\section{ACKNOWLEDGMENT}

The authors are grateful to IISER Bhopal for XRD and HRFESEM analysis.

\section{REFERENCES}

[1] C.D.S. Tomlin (Ed.), "The Pesticide Manual", 13 Ed, BCPC, Hampshire, pp 697-698, 2006.

[2] S. Malato, J. Blanco, J. C'aceres, A.R. Fern'andez-Alba, A. Ag"uera, A. Rodr'1guez, "Photocatalytic treatment of watersoluble pesticides by photo-Fenton and $\mathrm{TiO}_{2}$ using solar energy", Catal. Today, vol 76, pp 209-220, 2002.

[3] S. Malato, J. Blanco, A. Vidal, D. Alarc'on, M.I. Maldonado, J. C'aceres, W. Gernjak, "Applied studies in solar photocatalytic detoxification: an overview", Sol. Energy, vol 75, pp 329-336, 2003.

[4] M. Tamimi, S. Qourzal, A. Assabbane, J.-M. Chovelon, C. Ferronato, Y. Ait-Ichou, "Photocatalytic degradation of pesticide methomyl: determination of the reaction pathway and identification of intermediate products", Photochem. Photobiol. Sci., vol 5, pp 477- 482, 2006.

[5] I. Oller, W. Gernjak, M.I. Maldonado, L.A. Pérez-Estrada, J.A. Sánchez-Pérez, S. Malato, "Solar photocatalytic degradation of some hazardous water-soluble pesticides at pilot-plant scale”, J. Hazard. Mater., vol B 138,pp 507-517, 2006.

[6] A.Tomašević, D. Mijin and E.Kiss, "Photochemical Behavior of the Insecticide Methomyl Under Different Conditions", Separation Science and Technology, vol 45, pp 1617 -27, 2010.

[7] R.-S. Juang and C.-H.Chen, "comparative study on photocatalytic degradation of methomyl and parathion over UV-irradiated $\mathrm{TiO}_{2}$ particles in aqueous solutions", Journal of the Taiwan Institute of Chemical Engineers, vol. 45, Issue 3, pp 989- 995, 2014.

[8] N. A. M.Barakat, M. M.Nassar, T. E. Farrag and M. S. Mahmoud, "effective photodegradation of methomyl pesticide in concentrated solutions by novel enhancement of the photocatalytic activity of $\mathrm{TiO}_{2}$ using $\mathrm{CdSO}_{4}$ nanoparticles”, Environ SciPollut Res, vol. 21, pp 1425-1435, 2014.

[9] A.Tomašević, D.Mijin, S. Gašic and E.Kiss, "the influence of polychromatic light on methomyl degradation in $\mathrm{TiO}_{2}$ and $\mathrm{ZnO}$ aqueous suspension", Desalination and Water Treatment, vol. 52, pp 4342-4349, 2014.

[10] M. Tamimi, S. Qourzal, N. Barka, A. Assabbane, Y. Ait-Ichou, "Methomyl degradation in aqueous solutions by Fenton's reagent and the photo-Fenton system", Separation and Purification Technology, vol. 61,pp 103-108, 2008.

[11] A .R. Fernández-Alba, D. Hernando, A. Agüera, J. Cáceres, S. Malato, "Toxicity assays: a way for evaluating AOPs efficiency", Water Res., vol. 36, pp 4255- 4262, 2002. 
[12] A. Tomaš ević, G. Bošković, D. Mijin, E.E. Kiss, "Decomposition of methomyl over supported iron catalysts", React. Kinet. Catal. Lett., vol. 91, pp 53-59, 2007.

[13] A Tomašević, E Kiss, S Petrović , D Mijin, "Study on the photocatalytic degradation of insecticide methomyl in water", Desalination, vol. 262, pp 228-234, 2010.

[14] A. Zapata, I. Oller, E. Bizani, J. A. Sanchez-Perez, M. I. Maldonado, S. Malato, "Evaluation of operational parameters involved in solar photo-Fenton degradation of a commercial pesticide mixture", Catalysis Today, vol. 144, pp 94-99, 2009.

[15] Fares A. Al Momani, Ahmad T. Shawaqfeh, Mo“ ayyed S. Shawaqfeh, "Solar wastewater treatment plant for aqueous solution of pesticide”, Solar Energy, vol. 81, pp 1213-1218, 2007.

[16] S. Malato, P. Fernandez-Ibanez, M.I. Maldonado, J. Blanco, W. Gernjak, "Decontamination and disinfection of water by solar photocatalysis: Recent overview and trends", Catalysis Today, vol. 147, pp 1- 59, 2009.

[17] P. Ye , J. Xie, Y. He, L. Zhang, T. Wu, Y. Wu, "Hydrolytic synthesis of flower like BiOCl and its photocatalytic performance under visible light", Materials Letters, vol. 108, pp 168-171, 2013.

[18] Z. Y. Jiang, Q. Kuang, Z. X. Xie, L. S. Zheng, " Syntheses and Properties of Micro/Nanostructured Crystallites with High-Energy Surfaces", Advanced Functional Materials, vol. 20 Issue 21, pp 3634-3645, 2010

[19] M. S. S. Dorraji, N. Daneshavar and S. Aber, "Influence of inorganic oxidants and metal ions on photocatalytic activity of prepared zinc oxide nanocrystals”, J. Glob. Nest, vol. 11, Issue 4,pp 535-545, 2009.

[20] F. Sayılkan, M. Asiltürk, P. Tatar, N. Kiraz, S. Sener, E. Arpac and $\mathrm{H}$. Saylkan, "Photocatalytic performance of Sn-doped $\mathrm{TiO}_{2}$ nanostructured thin films for photocatalytic degradation of malachite green dye under UV and VIS-lights", Mater. Res. Bull., vol. 43 Issue 1,pp 127-134, 2008.

[21] I. Poulios, A. Avranas, E. Rekliti and A. Zouboulis, "Photocatalytic oxidation of Auramine $O$ in the presence of semiconducting oxides”, J. Chem. Technol. Biotechnol., vol. 75, pp 205-212, 2000.

[22] B. Pare, P. Singh and S. B. Jonnalagadda, "Visible light induced heterogeneous advanced oxidation process to degrade pararosanilin dye in aqueous suspension of $\mathrm{ZnO}$ ”, Indian J Chem A, vol. 47A, Issue 6, pp 830-835, 2008.

[23] B. Pare, P. Singh and S. B. Jonnalgadda, "Degradation and mineralization of victoria blue $B$ dye in a slurry photoreactor using advanced oxidation process”, J. Scient. Ind. Res., vol. 68, Issue 8, pp 724-729, 2009.

[24] M. A. Benajady, N. Modirshala and R. Hamzavi, "Kinetic study on photocatalytic degradation of C.I. Acid Yellow 23 by ZnOphotocatalyst”, J. Hazard. Mat., vol. 133. Issue 1-3, pp 226232, 2006.

[25] D. Ma, S. Huang, W. Chen, S. Hu, F. Shi, and K. Fan, "SelfAssembled Three-Dimensional Hierarchical Umbilicate $\mathrm{Bi}_{2} \mathrm{WO}_{6}$ Microspheres from Nanoplates: ControlledSynthesis, Photocatalytic Activities, and Wettability”, J. Phys. Chem. C, vol. 113, Issue 11, pp 4369-4374, 2009.

[26] H. Li, Z. Bian, J. Zhu, D. Zhang, G. Li, Y. Huo, H. Li, and Y. Lu, "Mesoporous Titania Spheres with Tunable Chamber Stucture and Enhanced Photocatalytic Activity”, J Am Chem Soc, vol. 129, Issue 27 , pp 8406- 7, 2007.

[27] K. L. Zhang, C. M. Liu, F. Q. Huang, C. Zheng and W. D. Wang, "Study of the electronic structure and photocatalytic activity of the BiOCl photocatalyst" , Appl. Catal. B Environ., vol. 68, Issue 3-4, pp 125-129, 2006. 